\title{
Transport in a microfluidic catalytic reactor
}

Park, Hyung Gyu; Chung, Jaewon; Grigoropoulos, Costas P.; Greif, Ralph; Havstad, Mark; and Morse, Jeffrey D.

This article was submitted to

2003 ASME Summer Heat Transfer Conference, Las Vegas, Nevada, USA,

July $21-23,2003$

\section{June 12, 2003}

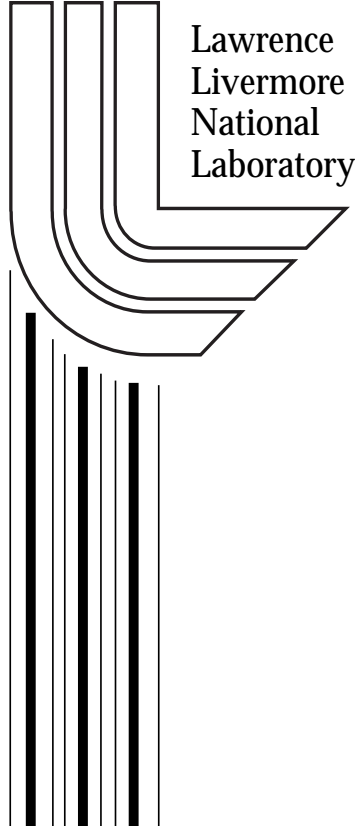




\section{DISCLAIMER}

This document was prepared as an account of work sponsored by an agency of the United States Government. Neither the United States Government nor the University of California nor any of their employees, makes any warranty, express or implied, or assumes any legal liability or responsibility for the accuracy, completeness, or usefulness of any information, apparatus, product, or process disclosed, or represents that its use would not infringe privately owned rights. Reference herein to any specific commercial product, process, or service by trade name, trademark, manufacturer, or otherwise, does not necessarily constitute or imply its endorsement, recommendation, or favoring by the United States Government or the University of California. The views and opinions of authors expressed herein do not necessarily state or reflect those of the United States Government or the University of California, and shall not be used for advertising or product endorsement purposes.

This is a preprint of a paper intended for publication in a journal or proceedings. Since changes may be made before publication, this preprint is made available with the understanding that it will not be cited or reproduced without the permission of the author.

This report has been reproduced directly from the best available copy.

A vailable electronically at http:/ / www.doc.gov/ bridge

A vailable for a processing fee to U.S. Department of Energy

And its contractors in paper from

U.S. Department of Energy

Office of Scientific and Technical Information

P.O. Box 62

Oak Ridge, TN 37831-0062

Telephone: (865) 576-8401

Facsimile: (865) 576-5728

E-mail: reports@adonis.osti.gov

A vailable for sale to the public from

U.S. Department of Commerce

National Technical Information Service

5285 Port Royal Road

Springfield, VA 22161

Telephone: (800) 553-6847

Facsimile: (703) 605-6900

E-mail: orders@ntis.fedworld.gov

Online ordering: http:/ / www.ntis.gov/ ordering.htm

OR

Lawrence Livermore National Laboratory

Technical Information Department's Digital Library

http:/ / www.Ilnl.gov/ tid/ Library.html 
University of California

Lawrence Livermore National Laboratory

Technical Information Department

Livermore, CA 94551

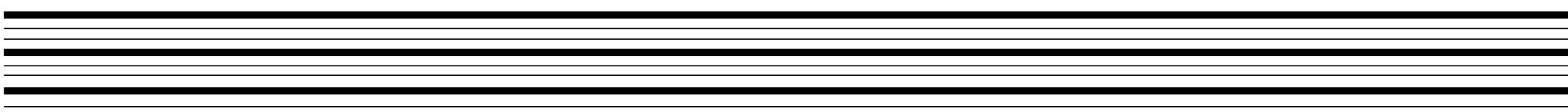


HT2003-47216

\title{
TRANSPORT IN A MICROFLUIDIC CATALYTIC REACTOR
}

\author{
Hyung Gyu Park, Jaewon Chung, Costas P. Grigoropoulos*, Ralph Greif \\ Department of Mechanical Engineering \\ University of California at Berkeley \\ Berkeley, CA 94720, USA \\ *Phone: (510) 642-2525, Fax: (510) 642-6163, Email: cgrigoro@me.berkeley.edu \\ Mark Havstad, Jeffrey D. Morse \\ Lawrence Livermore National Laboratory \\ Center for Microtechnology, 7000 East Avenue, L-223 \\ Livermore, CA 94550
}

\begin{abstract}
A study of the heat and mass transfer, flow, and thermodynamics of the reacting flow in a catalytic microreactor is presented. Methanol reforming is utilized in the fuel processing system driving a micro-scale proton exchange membrane fuel cell. Understanding the flow and thermal transport phenomena as well as the reaction mechanisms is essential for improving the efficiency of the reforming process as well as the quality of the processed fuel. Numerical studies have been carried out to characterize the transport in a silicon microfabricated reactor system. On the basis of these results, optimized conditions for fuel processing are determined.
\end{abstract}

\section{NOMENCLATURE}

$A, B \quad$ Pre-exponential term in Arrhenius expression for $k_{\mathrm{i}}^{4}$

$C \quad$ Molar concentration $\left(\mathrm{kmol} / \mathrm{m}^{3}\right)$

$c_{\mathrm{p}} \quad$ Heat capacity $(\mathrm{J} / \mathrm{kg} \mathrm{K})$

$D \quad$ Mass diffusivity $\left(\mathrm{m}^{2} / \mathrm{s}\right)$

$D_{\mathrm{p}} \quad$ Catalyst particle size (m)

$E_{\mathrm{i}} \quad$ Activation energy in Arrhenius expression for $k_{\mathrm{i}}^{4}$

$k \quad$ Forward rate constant: prime means reverse $\left(\mathrm{s}^{-1}\right.$ for reforming, and $\mathrm{kmol} / \mathrm{m}^{3} \mathrm{~s}$ for decomposition)

$M \quad$ Molar weight $(\mathrm{kg} / \mathrm{kmol})$

$m \quad$ Mass fraction

$P \quad$ Pressure $(\mathrm{Pa})$

$r \quad$ Radial coordinate (m)

$\dot{r}^{\prime \prime \prime} \quad$ Rate of production $\left(\mathrm{kmol} / \mathrm{m}^{3} \mathrm{~s}\right)$

$\bar{R} \quad$ Gas constant: $8314 \mathrm{~J} / \mathrm{kmol} \mathrm{K}$
S Source term (appropriate unit)

SMR Steam to methanol molar ratio

$T \quad$ Temperature $\left(\mathrm{K},{ }^{\circ} \mathrm{C}\right)$

$u \quad$ Velocity $(\mathrm{m} / \mathrm{s})$

u Velocity vector $(\mathrm{m} / \mathrm{s})$

$w_{\text {cat }}^{\prime \prime \prime} \quad$ Catalyst density $\left(\mathrm{kg}_{\text {cat }} / \mathrm{m}^{3}\right)$

$x \quad$ Mole fraction

$z \quad$ Axial coordinate (m)

Greek letter

$\epsilon \quad$ Porosity or void volume fraction

$\Gamma \quad$ Thermal conductivity (W/m K)

$\eta \quad$ Conversion efficiency or index

$\mu \quad$ Molecular viscosity $(\mathrm{kg} / \mathrm{m} \mathrm{s})$

$\rho \quad$ Density $\left(\mathrm{kg} / \mathrm{m}^{3}\right)$

$\xi \quad$ Reactor coordinate, along the channel (mm)

$\xi^{*} \quad$ Nondimensionalized reactor coordinate, $\xi /\left(u_{\text {in }} / k_{\mathrm{R}}\right)$

Subscripts

in, out Property or variable at inlet and outlet

i $\quad$ Species index $\left(1: \mathrm{CH}_{3} \mathrm{OH}, 2: \mathrm{H}_{2} \mathrm{O}, 3: \mathrm{H}_{2}, 4: \mathrm{CO}_{2}, 5: \mathrm{CO}\right)$

$f \quad$ Fluid

$s \quad$ Solid

$\mathrm{mtm} \quad$ Momemtum equation

cat Catalyst

CR Chemical reaction

$\mathrm{R} \quad$ Reforming reaction

D Decomposition reaction

W Water-gas shift reaction 


\section{INTRODUCTION}

Over the past two decades, there has been increased research in proton exchange membrane fuel cell (PEMFC). Since the application in the Gemini spacecraft, the technology has mostly been developed for large-scale systems such as a vehicle energy source. Recently, however, miniature PEMFC have experienced renewed interest for applications in portable power generation, which includes the full range of usage from consumer electronics such as cell phones, laptop computers, video camcorders, and radios, to military applications such as micro-scale field energy sources for various sensors and remote communication devices. ${ }^{1}$

The PEMFC employs hydrogen as its primary fuel. Because of safety and storage problems, direct hydrogen supply is less preferable than on-board generation. Several fuel candidates for the on-board generation of hydrogen rich gas have been investigated; ${ }^{2,3}$ methanol steam reforming has been preferred due to the lack of inter carbon bonds in methanol, to the limited carbon monoxide production, and to a higher hydrogen fraction in the reformate than that of partial oxidation. Should methanol steam reforming be chosen as the on-board hydrogen generation method for the miniature PEMFC, a micro-scale reformer may be necessary in the system. A MEMS based micro reformer has the advantages of fabricating small features, of integrating many components in a coherent way, of obtaining microfluidic stability due to small Reynolds number, and of requiring relatively low heating energy owing to its small size. Because of these advantages, it is reasonable to expect that micro reformers will be developed for the eventual integration of micro fuel cell systems.

According to Amphlett et al., ${ }^{4}$ methanol experiences two overall reactions in the reformer in the presence of $\mathrm{Cu} / \mathrm{ZnO} / \mathrm{Al}_{2} \mathrm{O}_{3}$ catalyst:

$$
\begin{aligned}
\mathrm{CH}_{3} \mathrm{OH}+\mathrm{H}_{2} \mathrm{O} \stackrel{k_{\mathrm{R}}}{\longrightarrow} \mathrm{CO}_{2}+3 \mathrm{H}_{2} \\
\mathrm{CH}_{3} \mathrm{OH} \stackrel{k_{\mathrm{D}}}{\longrightarrow} \mathrm{CO}+2 \mathrm{H}_{2}
\end{aligned}
$$

Reaction (1), called reforming, is a primary reaction in the methanol steam reforming process. Some portion of the methanol decomposes to produce carbon monoxide via reaction (2). In the presence of water, the three products adjust their compositions via the water-gas shift reaction:

$$
\mathrm{CO}+\mathrm{H}_{2} \mathrm{O} \underset{k_{\mathrm{w}}{ }^{\prime}}{\stackrel{k_{\mathrm{W}}}{\longleftrightarrow}} \mathrm{CO}_{2}+\mathrm{H}_{2}
$$

For PEMFC application, the reformer working temperature varies from 200 to $300^{\circ} \mathrm{C}$, where the dry product composition is such that the proportions of $\mathrm{H}_{2} / \mathrm{CO}_{2} / \mathrm{CO}$ are approximately $74 / 24 / 2$ by volume. ${ }^{4}$

One of the essential issues occurring with a micro reformer in a PEMFC is CO contamination. However small, $\mathrm{CO}$ always exists in the reformate due to reaction (2), which will poison and ultimately deactivate a Pt catalyzed anode of a PEMFC. Since the poisoning amount of $\mathrm{CO}$ is a few tens of ppm, it is very important to determine accurately the small amount of $\mathrm{CO}$ produced.

Fluid dynamics issues with a micro reformer include the pressure drop between inlet and outlet, which is related to the microfluidic pumping power as well as the chemical reaction rate. Of course, this problem depends on how the catalysts are distributed. If the catalysts are distributed on the reactor surface, pressure drop is not a concern. However, pressure drop may become an issue if catalysts are filled inside a channel because they will then act as flow resistances.

Since a micro reformer operates at a few hundred degrees Celsius, thermal management is also important. Efficient heat integration as well as thermal isolation is primary consideration in a miniature fuel cell for portable applications. The temperature inside the reformer channel is directly related to the reaction rate. An inefficient heating distribution would result in a negative effect on the reformer products, decreasing fuel cell performance. Thus, it is necessary to investigate the heat transfer on and inside the micro reformer.

In order to understand the chemical reactions, fluid mechanics, and heat/mass transfer in a micro reformer, we will choose both analytical and CFD (Computational Fluid Dynamics) approaches in the present study. First, a theoretical analysis based on chemical reactions and transport will be presented. A CFD based simulation for a plug flow reactor will be carried out to compare with the theoretical model that is based on the reaction kinetics by Amphlett et al. ${ }^{4}$ Finally, a three-dimensional analysis of a typical serpentine type micro reformer will be made and compared with preliminary experimental data.

\section{THEORETICAL ANALYSIS}

In order to understand the transport phenomena in a chemically reacting channel, a theoretical analysis is presented based on stoichiometry and mass transport. We focus on the reforming reaction (1) for this consideration. The concepts are schematically shown in Table 1 and Fig. 1, where constant pressure and temperature are assumed. Once we determine the mole fractions of the four species in Table 1, we will decouple reaction (2) from (1) and determine the mole fraction of $\mathrm{CO}$.

The chemical reaction kinetics of Amphlett et al. ${ }^{4}$ was chosen for this study. These authors claimed that reactions (1) and (2) are irreversible, as the equilibrium conversion of methanol is virtually $100 \%$. They also asserted that the watergas shift reaction, or reaction (3) can be neglected without substantial loss of accuracy under conditions similar to those considered in this work. If we assume further a constant 
pressure of $1 \mathrm{~atm}$, which is typical for the small-scale plug flow reactor, we may exclude the pressure dependence in their chemical rate constants. Accordingly, the rate constants determined are as follows:

$$
\begin{gathered}
\dot{r}_{\mathrm{R}}^{\prime \prime \prime}=k_{\mathrm{R}} C_{1}, \quad \dot{r}_{\mathrm{D}}^{\prime \prime \prime}=k_{\mathrm{D}} \\
k_{\mathrm{R}}=\bar{k}_{\mathrm{R}} w_{\text {cat }}^{\prime \prime \prime}, \quad k_{\mathrm{D}}=\bar{k}_{\mathrm{D}} w_{\text {cat }}^{\prime \prime \prime} \\
\bar{k}_{\mathrm{R}}=\left[A_{\mathrm{R}}+B_{\mathrm{R}} \ln (\mathrm{SMR})\right] \exp \left[-\frac{E_{\mathrm{R}}}{\bar{R} T}\right] \\
\bar{k}_{\mathrm{D}}=A_{\mathrm{D}} \exp \left[-\frac{E_{\mathrm{D}}}{\bar{R} T}\right]
\end{gathered}
$$

Because $k_{\mathrm{D}}$ is independent of the molar concentrations of any of the species, the production of carbon monoxide is not related to the concentration of the other components. Therefore, with the neglect of the water-gas shift reaction, the decoupling of reaction (2) is justified when the decomposition reaction is much slower than reforming.

One-dimensional mass transport equation neglecting mass diffusion among species yields

$$
\frac{d}{d z}\left(C_{\mathrm{i}} u\right)=\dot{r}_{\mathrm{i}}^{\prime \prime \prime}
$$

For methanol, $\dot{r}_{1}^{\prime \prime \prime}=-\dot{r}_{\mathrm{R}}^{\prime \prime \prime}=-k_{\mathrm{R}} C_{1}=-k_{\mathrm{R}}(P / \bar{R} T) x_{1}$. Thus,

$$
\frac{d}{d z}\left(x_{1} u\right)=-k_{\mathrm{R}} x_{1}
$$

Recalling that $u$ and $x_{1}$ are both functions of $\eta$ in Table 1,

$$
\frac{d z}{d \eta}=\frac{u_{\mathrm{in}}}{k_{\mathrm{R}}}\left(-1+\frac{2}{1-\eta}\right)
$$

Utilizing the boundary condition of $z(\eta=0)=0$, the solution is

$$
\frac{z(\eta)}{u_{\mathrm{in}} / k_{\mathrm{R}}}=-\eta-2 \ln (1-\eta)
$$

which is shown in Fig. 2(a). The parameter $u_{\text {in }} / k_{\mathrm{R}}$ is the characteristic length scale for the methanol-water mixture gas in the reactor. Methanol is converted rapidly in the near inlet region, where the conversion efficiency is linearly proportional to a nondimensional reactor coordinate, $k_{\mathrm{R}} z / u_{\mathrm{in}}$. As indicated in eq. (4a), the reforming reaction rate is proportional to the methanol concentration. As the reactant-product mixture gas flows downstream, the methanol concentration decreases resulting in the gradual increase of the conversion efficiency up to $100 \%$. From eq. (11) and Fig. 2(a), the required length for $99 \%$ conversion is 8.22 times the characteristic length, $u_{\mathrm{in}} / k_{\mathrm{R}}$.

$$
\frac{z(99 \%)}{u_{\text {in }} / k_{\mathrm{R}}}=8.22
$$

Eq. (11) or the relation between the reactor coordinate $\mathrm{z}$ and the conversion efficiency is used to represent mole fractions, molar weight, mass density and velocity as functions of the reactor coordinate. For the methanol mole fraction, $x_{1}=$ $(1-\eta) / 2(1+\eta)$, or $\eta=-1+2 /\left(2 x_{1}+1\right)$. Substitution of this relation for $\eta$ into eq. (11) yields

$$
\frac{z}{u_{\mathrm{in}} / k_{\mathrm{R}}}=1-\frac{1}{x_{1}+\frac{1}{2}}-2 \ln \left(2-\frac{1}{x_{1}+\frac{1}{2}}\right) \text {. }
$$

The same results also apply to the water mole fraction, $x_{2}$. In a similar way, we determine the variation of the other variables with respect to $z$ :

$$
\frac{z}{u_{\text {in }} / k_{\mathrm{R}}}=\left\{\begin{array}{c}
1-\frac{1}{1-\frac{2}{3} x_{3}}-2 \ln \left(2-\frac{1}{1-\frac{2}{3} x_{3}}\right) \\
1-\frac{1}{1-2 x_{4}}-2 \ln \left(2-\frac{1}{1-2 x_{4}}\right) \\
1-\frac{25}{M}-2 \ln \left(2-\frac{25}{M}\right) \\
1-\frac{\rho_{\text {in }}}{\rho}-2 \ln \left(2-\frac{\rho_{\text {in }}}{\rho}\right) \\
1-\frac{u}{u_{\text {in }}}-2 \ln \left(2-\frac{u}{u_{\text {in }}}\right)
\end{array}\right.
$$

Fig.'s 2(b) and 2(c) show these results. Since $S M R=1$, the mole fractions of methanol and water are the same; both decrease rapidly near inlet ( $z$ close to 0 ) and go to zero downstream asymptotically. Mole fractions of hydrogen and carbon dioxide increase rapidly at the beginning and reach their asymptotes: 0.75 for $\mathrm{H}_{2}$ and 0.25 for $\mathrm{CO}_{2}$ corresponding to the values at $100 \%$ conversion. Although pressure and temperature are assumed to be constant, the ideal gas mixture density decreases due to the change of average molar weight. The apparent flow velocity increases in order to meet overall mass conservation, so that $\rho u$ is constant.

The estimation of the concentration of carbon monoxide is important because amounts as small as a few tens of ppm may easily poison the Pt-coated anode of PEMFC, deactivating the Pt catalyst. The analysis here will take advantage of the fact that the molar changes, via reaction (2), of all the components except that of carbon monoxide are negligible compared with those via reaction (1). ${ }^{4}$ For carbon monoxide, the reaction rate source in eq. (8) is $\dot{r}_{5}^{\prime \prime \prime}=\dot{r}_{\mathrm{D}}^{\prime \prime \prime}=k_{\mathrm{D}}$. The transport equation of carbon monoxide is, therefore, given by 


$$
\frac{d}{d z}\left(C_{5} u\right)=k_{\mathrm{D}}
$$

For an ideal gas, $C_{5}=x_{5} P / \bar{R} T$, and

$$
\frac{d}{d z}\left(x_{5} u\right)=\frac{\bar{R} T}{P} k_{\mathrm{D}}
$$

Eq. (15) with the boundary condition of $x_{5}(z=0)=0$ is solved to yield

$$
x_{5}=\frac{k_{\mathrm{D}} / k_{\mathrm{R}}}{P / \bar{R} T} \cdot \frac{z}{u(z) / k_{\mathrm{R}}} .
$$

Combining eq. (16) with eq. (14e), we obtain a relation between the reactor coordinate and $x_{5}$ as follows:

$$
\frac{z}{u_{\text {in }} / k_{\mathrm{R}}}=\left(1+\frac{k_{\mathrm{D}} / k_{\mathrm{R}}}{x_{5} P / \bar{R} T}\right)^{-1}\left[1-2 \ln \left(2-\frac{k_{\mathrm{D}} / k_{\mathrm{R}}}{x_{5} P / \bar{R} T} \frac{z}{u_{\text {in }} / k_{\mathrm{R}}}\right)\right] .
$$

This equation may be approximated as:

$$
x_{5} \cong \frac{k_{\mathrm{D}} / k_{\mathrm{R}}}{P / \bar{R} T} \cdot \frac{z /\left(u_{\text {in }} / k_{\mathrm{R}}\right)}{2-\exp \left[-z /\left(2 u_{\text {in }} / k_{\mathrm{R}}\right)\right]} .
$$

The functional form of eq. (18) indicates that the mole fraction of carbon monoxide varies linearly far from the inlet region. Near the inlet, $x_{5}$ takes the form of a rational function with a slope two times larger than that for the downstream solution. Dividing eq. (18) by $x_{1}$ yields:

$$
\begin{aligned}
\frac{x_{5}}{x_{1}} & \cong \frac{k_{\mathrm{D}}}{k_{\mathrm{R}} x_{1} P / \bar{R} T} \cdot \frac{z /\left(u_{\mathrm{in}} / k_{\mathrm{R}}\right)}{2-\exp \left[-z /\left(2 u_{\mathrm{in}} / k_{\mathrm{R}}\right)\right]} \\
& =\frac{\dot{r}_{\mathrm{D}}^{\prime \prime \prime}}{\dot{r}_{\mathrm{R}}^{\prime \prime \prime}} \cdot \frac{z /\left(u_{\mathrm{in}} / k_{\mathrm{R}}\right)}{2-\exp \left[-z /\left(2 u_{\mathrm{in}} / k_{\mathrm{R}}\right)\right]} .
\end{aligned}
$$

As seen in eq. (19), the magnitude of the ratio of the mole fraction of carbon monoxide to that of methanol is determined by the ratio of the reaction rates. If the methanol-steam reforming reaction is faster than the methanol decomposition reaction as assumed above, the carbon monoxide mole fraction will be lower than the methanol mole fraction. Using typical values yields that the resulting $\mathrm{CO}$ mole fraction is very small compared to the mole fractions of the other components: less than $3 \%$ at $z(99 \%)$.

\section{NUMERICAL ANALYSIS}

\section{Plug flow reactor}

A CFD based reacting flow analysis was carried out. A plug flow simulation offers the advantage of ease of comparison with either the theoretical analysis above or a onedimensional transport model. ${ }^{4}$ Therefore we address a plug flow reactor as a benchmark test. The objective of the plug flow simulation is to apply a CFD based heat and mass transfer analysis to the methanol-steam reforming reaction to provide a useful tool in modeling more complex micro reformers, and to verify the theoretical model developed above.

The geometry of the plug flow reactor is shown in Fig. 3, where it is represented as a porous cylinder with $R=1 / 16^{\prime \prime}=$ $1.59 \mathrm{~mm}$ and $L=8 \mathrm{~mm}$. Several assumptions were made:

(1) $\mathrm{Cu} / \mathrm{ZnO} / \mathrm{Al}_{2} \mathrm{O}_{3}$ catalysts are packed inside the reactor

(2) Flow is axisymmetric, laminar, and steady.

(3) Catalyst bed acts as a porous medium flow resistance.

(4) The bed is continuously distributed, thus the velocity field is an apparent profile.

(5) The bed is in local equilibrium; temperatures of bed particle and surrounding gas are the same.

(6) Reactions are homogeneous; volumetric reactions are assumed, which do not occur at the catalyst surface.

(7) Five species are taken as ideal gases.

(8) Reactions follow eq.'s (4)-(7).

\section{Governing equation}

The governing equations for the reacting flow in the methanol-steam reforming plug flow reactor are:

- mass conservation

$$
\nabla \cdot(\rho \mathbf{u})=0
$$

- momentum conservation

$$
\nabla \cdot(\rho \mathbf{u} \mathbf{u})=\nabla \cdot \mu(\mathbf{r}) \nabla \mathbf{u}-\nabla p+\mathbf{S}_{\mathrm{mtm}},
$$

where the momentum source is an additional pressure drop caused by the flow resistance due to the packed catalyst bed. The Ergun equation ${ }^{5}$ neglecting inertial resistance contribution was employed to represent the pressure drop.

$$
\mathbf{S}_{\mathrm{mtm}}=-\frac{150 \mu(1-\varepsilon)^{2}}{\varepsilon^{3} D_{p}^{2}} \mathbf{u}
$$

- energy transport

$$
\nabla \cdot\left(\rho \mathbf{u} c_{\mathrm{p}} T\right)=\nabla \cdot \Gamma(\mathbf{r}) \nabla T+\mathrm{S}_{\mathrm{CR}},
$$

where the thermal conductivity, $\Gamma(\mathrm{r})$, is a volume weighted average of the catalyst bed material $\left(\mathrm{Cu} / \mathrm{ZnO} / \mathrm{Al}_{2} \mathrm{O}_{3}\right)$ and the gas mixture.

$$
\Gamma=\varepsilon \Gamma_{f}+(1-\varepsilon) \Gamma_{\mathrm{s}}
$$


Endothermic reactions in the reformer result in an energy sink that can be represented as

$$
\mathrm{S}_{\mathrm{CR}}=-\Delta H_{\mathrm{R}} \dot{r}_{\mathrm{R}}^{\prime \prime \prime}-\Delta H_{\mathrm{D}} \dot{r}_{\mathrm{D}}^{\prime \prime \prime}
$$

- species transport

$$
\nabla \cdot\left(\rho \mathbf{u} m_{\mathrm{i}}\right)=\nabla \cdot \rho D_{\mathrm{i}}(\mathbf{r}) \nabla m_{\mathrm{i}}+\frac{\dot{r}_{\mathrm{i}}^{\prime \prime \prime}}{M_{\mathrm{i}}}
$$

The mass diffusivity, $D_{\mathrm{i}}$, for the multicomponent diffusion is determined, using the binary diffusion coefficient, $D_{\mathrm{ij}}$, by ${ }^{7}$

$$
D_{\mathrm{i}}=\frac{1-x_{\mathrm{i}}}{\sum_{\mathrm{j}, \mathrm{j} \neq \mathrm{i}}\left(x_{\mathrm{j}} / D_{\mathrm{ij}}\right)}
$$

Catalyst density required for determining reaction rate constants in eq. $(5 \mathrm{a}, \mathrm{b})$ is $9.5 \times 10^{-4} \mathrm{~kg}_{\text {cat }} / \mathrm{m}^{3}$.

Properties such as density, molecular viscosity, and thermal conductivity were calculated assuming an ideal gas mixture. Thus the density was calculated from

$$
\rho=\frac{P}{\bar{R} T} M=\frac{P}{\bar{R} T} \sum_{\mathrm{i}} x_{\mathrm{i}} M_{\mathrm{i}} .
$$

Wilke's formula ${ }^{6}$ was employed to calculate the molecular viscosity and thermal conductivity of an ideal gas mixture.

\section{Mesh generation and boundary conditions}

From the theoretical analysis above, the reforming reaction rate varies with the methanol molar concentration, while the decomposition rate does not. However, the dominant reaction is reforming ${ }^{4}$, which means the reaction rate is higher near the inlet where the methanol concentration is high compared with the concentration downstream. Also, should there be a radial gradient of any transport variable, it would be significant only near the reactor wall. Therefore, a nonuniform grid system was introduced in both radial and axial directions; 20 cells were specified in the radial direction and 40 axially.

The boundary conditions are as follows: at the inlet, values of all the variables are assigned:

$$
\rho \mathbf{u}=\rho_{\text {in }} \mathbf{u}_{\text {in }}, \quad m_{\mathrm{i}}=m_{\mathrm{i}, \text { in }}, \quad T=T_{\text {in }}
$$

The reactor wall is regarded as a no-slip, adiabatic, and impermeable surface:

$$
\left.\mathbf{u}\right|_{\mathrm{w}}=0,\left.\frac{\partial T}{\partial r}\right|_{\mathrm{w}}=0,\left.\frac{\partial m_{\mathrm{i}}}{\partial r}\right|_{\mathrm{w}}=0
$$

At the axis, the symmetry boundary condition was applied. Finally, at the outlet, a traction free or pressure boundary condition was applied with zero gauge pressure.

\section{Solution Algorithm}

The above governing equations and boundary conditions were solved using the finite volume method (FVM). The commercial CFD code FLUENT $^{7}$ and a research code TOPAZ3D ${ }^{8}$ developed at LLNL were utilized to carry out the simulation. The steady state flow through the porous medium accompanied by heat and mass transfer with chemical reactions were simultaneously solved by applying the SIMPLE $^{9}$ algorithm with the first order upwind scheme for combining and discretizing convection and diffusion terms.

\section{Results and model validation}

The one-dimensional variations of the velocity, pressure, and mole fractions were obtained in a plug flow reactor; the mole fraction of hydrogen is shown in Fig. 4. Since the reactor length is short and thus filled by only a small amount of catalysts, the input flow with high temperature, e.g. $543 \mathrm{~K}$, does not lose much energy, resulting in temperature difference less than $1 \mathrm{~K}$. Therefore, for this case, the constant temperature assumption is valid. Upon entering the reactor, the fluid experiences a large flow resistance caused by the catalytic bed, and the velocity profile along the channel is uniform. Even though the pressure gradient is high, the reactor length is small enough to render a small pressure drop along the reactor. Since the velocity has almost the one-dimensional plug flow profile, the mass transport characteristics are also one-dimensional. Thus only the chemical reaction provides the driving force for mass transport.

Under constant temperature and pressure, the calculated molar flow rates were compared with Amphlett et al. ${ }^{4}$. Fig. 5 shows agreement with them for each of the five different species to within $1 \%$.

With this verified model, we examined the effectiveness of the above theoretical analysis. Comparison of the mole fractions of the five components represented in Fig. 6 showed good agreement; thus, in a simple geometry, the theoretical calculation is sufficient for the estimation of the mass transport due to the present chemical reaction kinetics. The small deviation in the carbon monoxide mole fraction is attributed to the approximation in eq. (18).

By considering a CFD based heat and mass transfer simulation model and by applying it to a plug flow reactor, we developed a tool that is useful for analyzing a threedimensional reformer.

\section{Serpentine micro reactor}

Following the benchmark study, the transport in a MEMS based micro fluidic catalytic reformer is analyzed. The micro reformer considered is a serpentine type reactor designed to 
provide enough residence time for the reacting species. A $1 \mathrm{~mm}$ wide mesoscale channel is etched in a silicon substrate to $400 \mu \mathrm{m}$ depth in a serpentine shape to provide a catalytic reaction zone. $\mathrm{Cu} / \mathrm{ZnO} / \mathrm{Al}_{2} \mathrm{O}_{3}$ catalysts are filled inside the channel, and electric heaters on the other side of the substrate supply the required amount of heat into the channel across the silicon substrate. A $1 \mathrm{~mm}$ thick Pyrex glass covers the packed bed channel and the rest of the substrate surface. The substrate is $500 \mu \mathrm{m}$ thick. A liquid methanol-water mixture at room temperature enters the channel inlet and travels through an evaporator zone equipped with a heater. The methanol-water gas mixture is vaporized and flows into a packed-bed catalytic reaction zone at an assumed temperature of $100^{\circ} \mathrm{C}$. There, it will react in the presence of the catalyst particles to form hydrogen and carbon dioxide as the main products. Carbon monoxide is a byproduct caused by decomposition of methanol according to the present chemical kinetic model. ${ }^{4}$

\section{Geometry and mesh generation}

Fig. 7 shows the geometry for simulating the heat and mass transfer associated with the methanol-steam reforming reaction in a serpentine micro catalytic reformer. A reformer device has been fabricated and tested with a mesoscale channel etched in a $2.54 \mathrm{~cm} \times 2.54 \mathrm{~cm} \times 500 \mu \mathrm{m}$ silicon substrate and a $1 \mathrm{~mm}$ thick Pyrex glass cover. To save computing time, however, the glass cover was replaced by the one-dimensional thermal resistance boundary condition, assuming negligible transverse heat conduction ( $x$ and $y$ directions in Fig. 7) inside the cover. For ease of modeling, the portion of the channel filled with the liquid phase was removed in generating mesh and assigned the corresponding heat sink owing to convective transport of latent heat. Thus the geometry considered as a computational domain in this study includes only the channel and a silicon substrate. For the FVM analysis, the domain was divided into triangular cells: 33,000 fluid cells for the channel and 135,000 solid cells for the substrate.

\section{Governing equations and boundary conditions}

The governing equations for CFD with heat and mass transfer in the micro reformer are exactly the same as those used for the above plug flow reactor simulation, except that additional heat conduction through the silicon substrate is also included. Therefore, the governing equations are eq. (20) (24), plus the steady state heat conduction equation for the substrate:

$$
\nabla^{2} T=0
$$

Conjugate heat transfer at the interface of the fluid channel and the solid substrate is dealt with by equating the heat fluxes from both the fluid and solid sides.

The amount of catalyst filled inside the reformer is about $65 \mathrm{mg}$ in the packed bed channel volume of $5.0 \times 10^{-8} \mathrm{~m}^{3}$. Thus the catalyst density, $w_{\text {cat }}^{\prime \prime \prime}$, of $1,300 \mathrm{~kg}_{\text {cat }} / \mathrm{m}^{3}$ was used to calculate the reaction rate constants $k_{\mathrm{R}}$ and $k_{\mathrm{D}}$ in eq. (5a,b).

At the inlet, the mass flow rate of $1.43 \times 10^{-7} \mathrm{~kg} / \mathrm{s}$, inlet temperature of $100^{\circ} \mathrm{C}$, and mass fractions of water and methanol for the steam-to-methanol molar ratio of 1.1 are specified. The inlet mass flow rate corresponds to the liquid input of $10 \mu \mathrm{L} / \mathrm{min}$ at $20^{\circ} \mathrm{C}$. At the outlet, a pressure boundary condition was used. At the portion of the bottom substrate wall contacting the main heater, a constant heat flux condition corresponding to $2 \sim 4 \mathrm{~W}$ of main heater Joule heating was assigned. The portion of the bottom wall contacting the evaporator heater was constant heat flux for $18 \mathrm{~mW}$ corresponding to the convective latent heat of liquid mixture. The wall of the introduction part to the inlet was assigned the heat output from the substrate corresponding to the latent heat of the liquid methanol-steam mixture, instead of considering two-phase flow in detail. The other wall surfaces have natural convection boundary conditions with an ambient temperature of $20^{\circ} \mathrm{C}$.

\section{Results and discussion}

Fig. 8 shows the reforming reaction related characteristics of flow, heat, and mass transfer. The velocity and pressure vary along the channel in a similar manner to that for the plug flow reactor, except for the different behavior at the curved sites. In fig.'s 8(a) and (b), the pressure drop varies linearly downstream while the velocity field shows a local maximum inside each corner turn. This velocity phenomenon, called a "racing track effect," is one of the characteristics of a serpentine channel, which affects the convective heat and mass transfer inside of it. As the fluid flows pass through the curved part of the channel, the inner particles accelerate to acquire the same pressure drop in a relatively shorter path. When the flow emerges from the corner region into the straight channel part, inertia makes it sustain the nonuniform profile for a certain length depending on the flow conditions. The variables related to velocity are the convective heat and mass fluxes, $\rho \mathbf{u} c_{\mathrm{p}} T$ and $\rho \mathbf{u} m_{\mathrm{i}}$ respectively. The local transport of enthalpy and species concentration is also influenced by conduction and/or diffusion. For the heat flux, the racing track effect is not dominant because of heat conduction. However, for the mass flux, it does provide a primary mechanism along with the chemical reactions. Thus, the species concentration profile follows that of velocity near the curved sites, and flattens out in the straight regions after a certain distance depending on the flow condition. Overall, the longitudinal mass transport is dominated by chemical reactions, while the local lateral mass transport is affected by the racing track effect and diffusion. Illustrative examples are the mole fractions of the four main reactants and products with $x_{\mathrm{CH} 3 \mathrm{OH}}$ and $x_{\mathrm{H} 2}$ shown in Fig. $8(\mathrm{~d})$ and (e).

Due to the high thermal conductivity of silicon, the micro reformer maintains a relatively uniform temperature field. For a $3.3 \mathrm{~W}$ supply at the main heater, the temperature field is such that the average temperature is about $512 \mathrm{~K}$ with a temperature 
difference of about $15 \mathrm{~K}$ within $2.54 \mathrm{~cm}$. Temperature contours are shown in Fig. 8(c), and the temperature field along the channel coordinate is shown in Fig. 9.

An interesting feature is observed in comparing the two reactions. Fig.'s 8(f) and (g) illustrate the rates of reaction for two reactions: reforming [8(f)] and decomposition [8(g)]. As seen in eq. $(5 a, b)$, the first reaction rate is related to the concentration of methanol which is controlled by the velocity field. The second, however, does not depend on any components but on the temperature according to the Arrhenius relation. In Fig. 8(f), the rate of reaction (1) follows the velocity pattern, while that of reaction (2) follows the pattern of the temperature field as shown in Fig. 8(g). These features determine the behavior of the mole fraction variations along the channel that are displayed in Fig. 10. As recognized in the previous results, where temperature was fixed, the rates of consumption or production of methanol, water, hydrogen and carbon dioxide change along the channel. However, carbon monoxide seems to have a constant production rate, perhaps due to small temperature gradient in the reformer.

A theoretical solution based on the above conditions with SMR equal to 1.1 was developed and is displayed in Fig. 10. The solution is in a good agreement with the simulation results, which means the analytical method developed above can be applied to a serpentine channel to determine the variation of the average mole fraction.

The temperature variations of both the methanol conversion efficiency and the $\mathrm{CO}$ mole fraction are shown in Fig. 11. The conversion efficiency has a typical stretched $\mathrm{S}$ shape approaching $100 \%$ conversion at higher temperature with a similar trend shown for the experimental data, although there are quantitative differences. The $\mathrm{CO}$ mole fraction increases exponentially as a function of the reformer temperature. Therefore, when we consider the reformer as the fuel processor of a miniature PEMFC, the production of carbon monoxide may restrict the operating temperature.

\section{CONCLUSIONS}

Theoretical and CFD based heat and mass transfer analyses were carried out to study the reacting flow in a catalytic micro reformer. By decoupling the reforming and decomposing reactions, a simple and novel theoretical model was developed. It was demonstrated that the model is able to readily and accurately predict the flow and heat/mass transfer. The analysis may also be applied to a serpentine reactor to obtain average values across the cross sectional area. A numerical simulation for the reacting flow in a plug flow reactor was performed to validate the theoretical model.

The simulation was extended to a three-dimensional analysis of a micro catalytic reformer for a miniature PEMFC. The main features of the one-dimensional reacting flow results remained the same; however additional characteristics related to lateral transport were present. The direct conversion from reactants to products resulting from chemical reactions is the primary transport mechanism in the longitudinal direction, while a nonuniform velocity profile caused by the flow in the curved portions causes mass transport in the lateral direction.

The temperature is approximately constant in the reformer due to the high thermal conductivity of silicon. This may be a serious consideration with respect to the energy efficiency of a reformer-fuel cell pair.

The models developed in the present study can be utilized to carry out the design of thermally efficient reformers.

\section{ACKNOWLEDGMENTS}

This work was performed under the auspices of the U. S. Department of Energy by the University of California, Lawrence Livermore National Laboratory under Contract No. W-7405-Eng-48.

\section{REFERENCES}

1. Morse, J. D., Jankowski, A. F., Graff, R. T., and Hayes, J. P., J. Vac. Sci. Technol. A, 18(4), Jul/Aug 2000

2. Brown, L. F., Int. J. Hydrogen Engergy, 26, pp. 381397, 2001

3. Joensen, F. and Rostrup-Nielsen, J. R., J. Power Sources, 105, pp. 195-201, 2002

4. Amphlett, J. C., Creber, A. M., Davis, J. M., Mann, R. F., Peppley, B. A., and Stokes, D. M., J. Hydrogen Energy, 19(2), pp. 131-137, 1994

5. Rosner, D. E., Transport Processes in Chemically Reacting Flow Systems, Dover Publications, Inc., p. 321, 2000

6. Mills, A. F., Mass Transfer, Prentice-Hall Inc., 2001

7. Fluent User Guide v6, Fluent Inc., 2001

8. Shapiro, A. B., University of California, Lawrence Livermore National Laboratory, Rept. UCID-20484, 1985

9. Patankar, Numerical heat transfer and fluid flow, Hemisphere, 1980

\begin{tabular}{|c|c|c|c|c|c|c|c|}
\hline$n$ & $x_{1}$ & $x_{2}$ & $x_{3}$ & $x_{4}$ & $M$ & $O$ & $u$ \\
\hline$T$ & $\mathrm{CH}_{3} \mathrm{OH}$ & $\mathrm{H}_{2} \mathrm{O}$ & $\mathrm{H}_{2}$ & $\mathrm{CO}_{2}$ & & $\mu$ & $u$ \\
\hline 0 & 0.5 & 0.5 & 0 & 0 & 25 & $\rho_{\text {in }}$ & $u_{\text {in }}$ \\
\hline$\eta$ & $\frac{1-\eta}{2(1+\eta)}$ & $\frac{1-\eta}{2(1+\eta)}$ & $\frac{3 \eta}{2(1+\eta)}$ & $\frac{\eta}{2(1+\eta)}$ & $\frac{25}{1+\eta}$ & $\frac{\rho_{\mathrm{in}}}{1+\eta}$ & $\begin{array}{r}(1+\eta) \\
u_{\text {in }}\end{array}$ \\
\hline 1 & 0 & 0 & 0.75 & 0.25 & 12.5 & $0.5 \rho_{\text {in }}$ & $2 u_{\text {in }}$ \\
\hline
\end{tabular}

Table 1 Mole fractions, molar weight, mass density, and velocity as functions of a conversion index or efficiency, $\eta$.

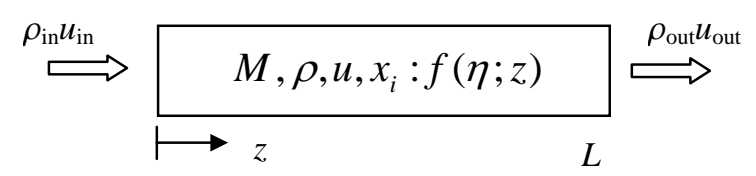

Fig. 1 Schematic and coordinates of the theoretical analysis 


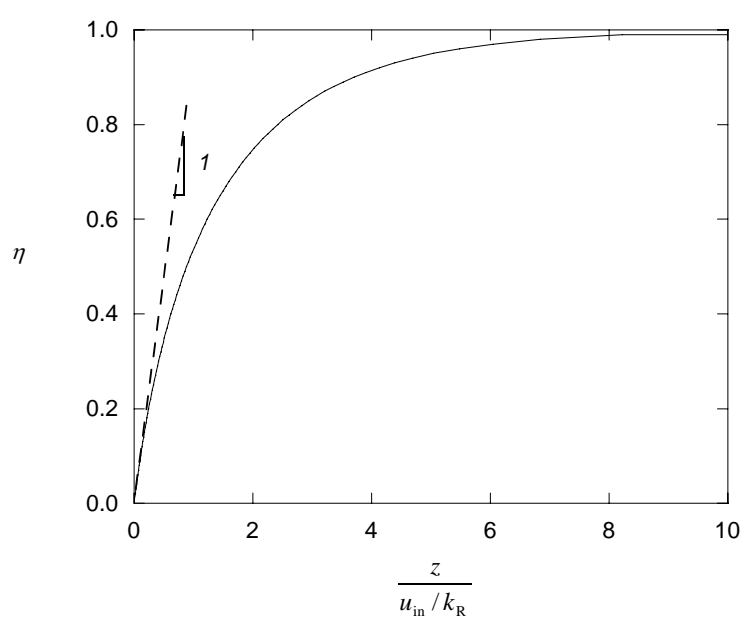

(a)

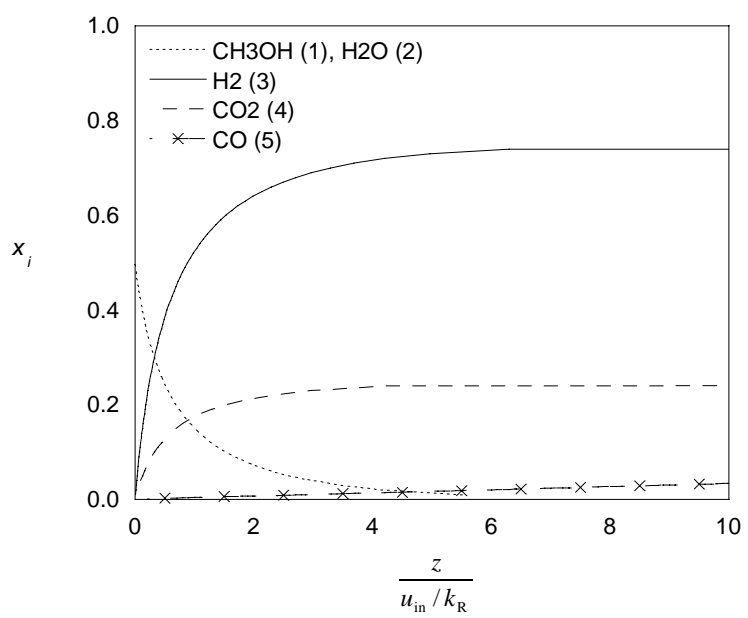

(b)

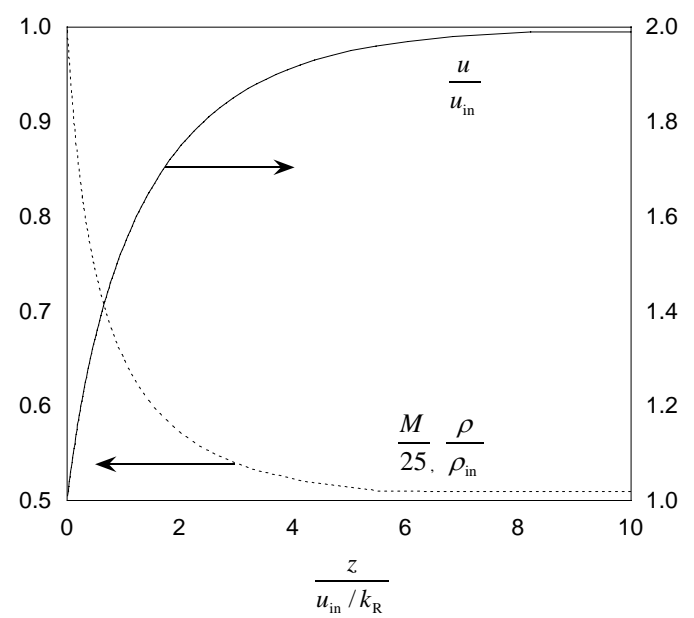

(c)

Fig. 2 (a) Conversion efficiency (index), (b) mole fractions, and (c) flow variables with respect to the nondimensional reactor coordinate

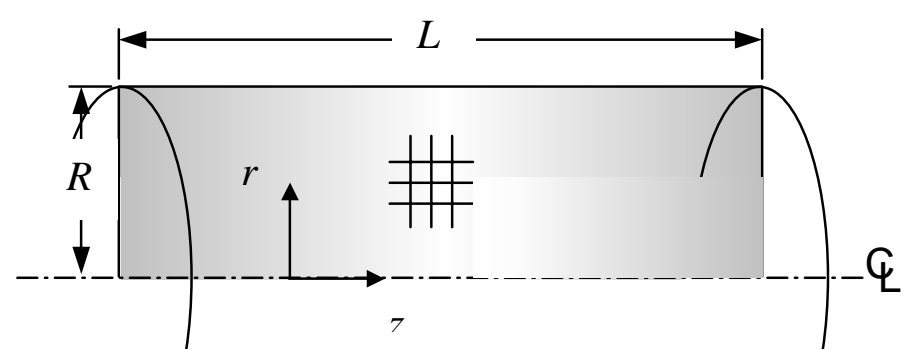

Fig. 3 A plug flow reactor

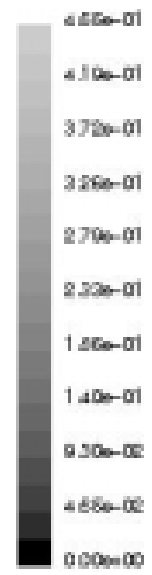

Fig. 4 Variation of the hydrogen mole fraction in a plug flow reactor

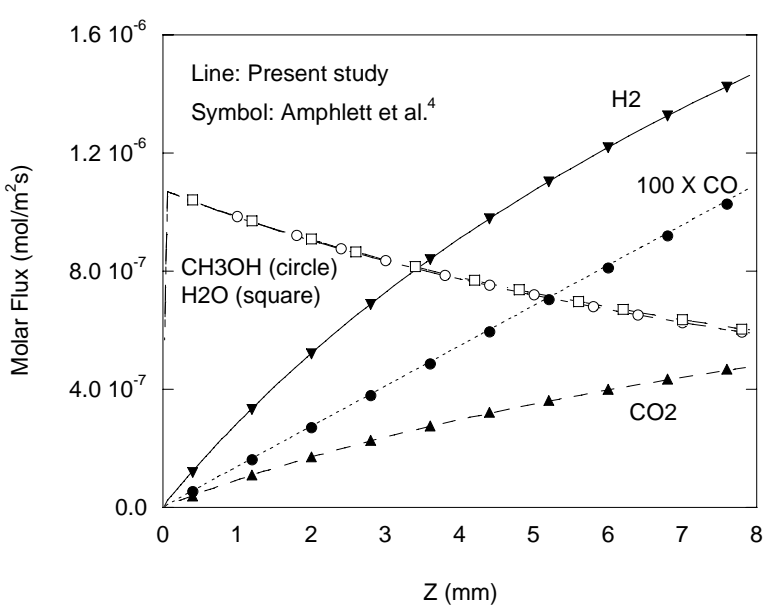

Fig. 5 Variation of molar fluxes with respect to the reactor coordinate: validation of model 


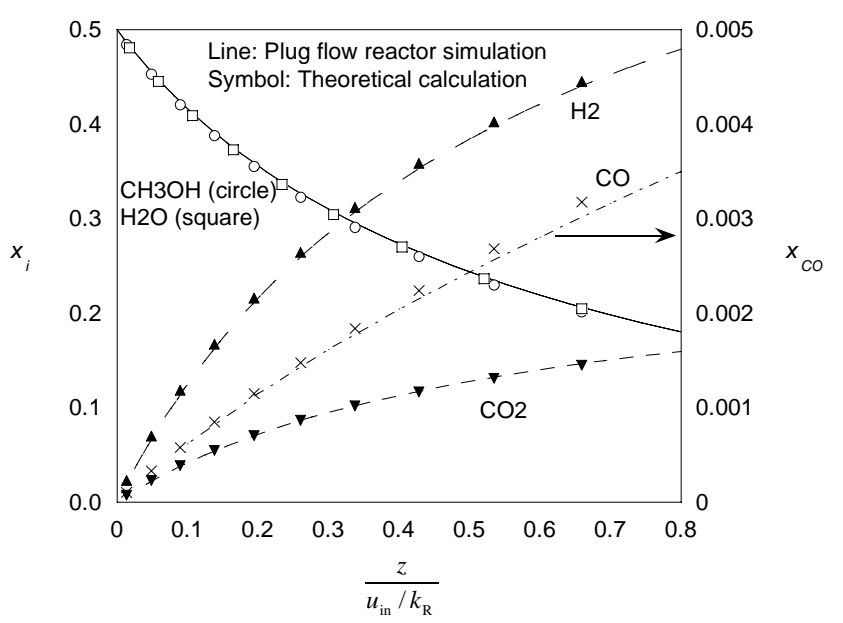

Fig. 6 Variation of mole fractions of five species: validation of theoretical analysis

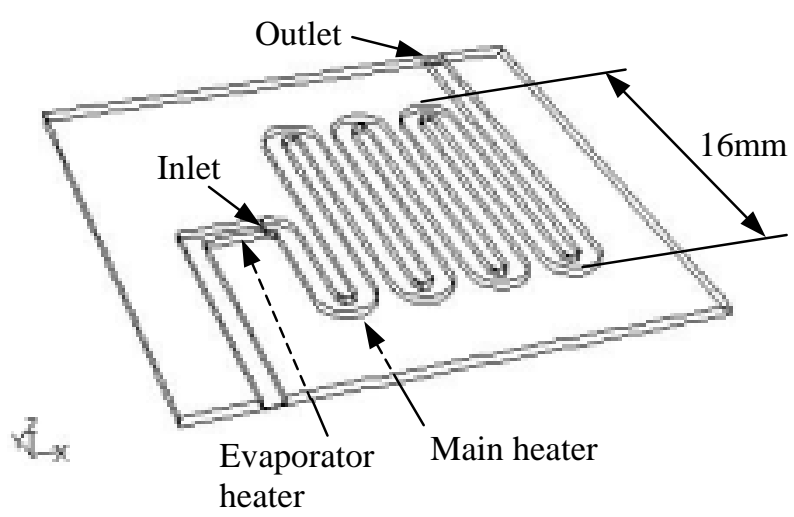

Fig. 7 A serpentine micro catalytic reformer channel, $1 \mathrm{~mm}$ wide, $400 \mu \mathrm{m}$ deep, and $15 \mathrm{~cm}$ long; the main heater follows the channel shape.

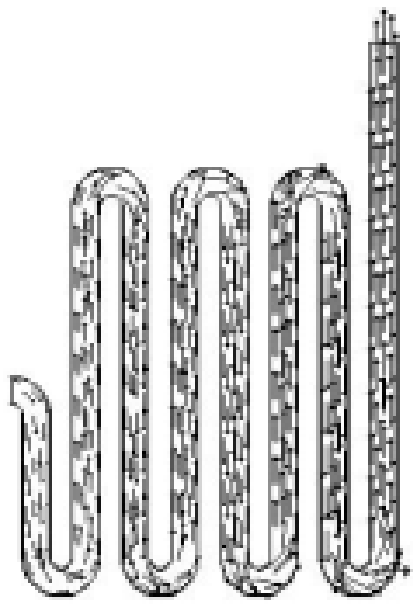

(a) apparent velocity $(0 \sim 1.6 \mathrm{~m} / \mathrm{s})$

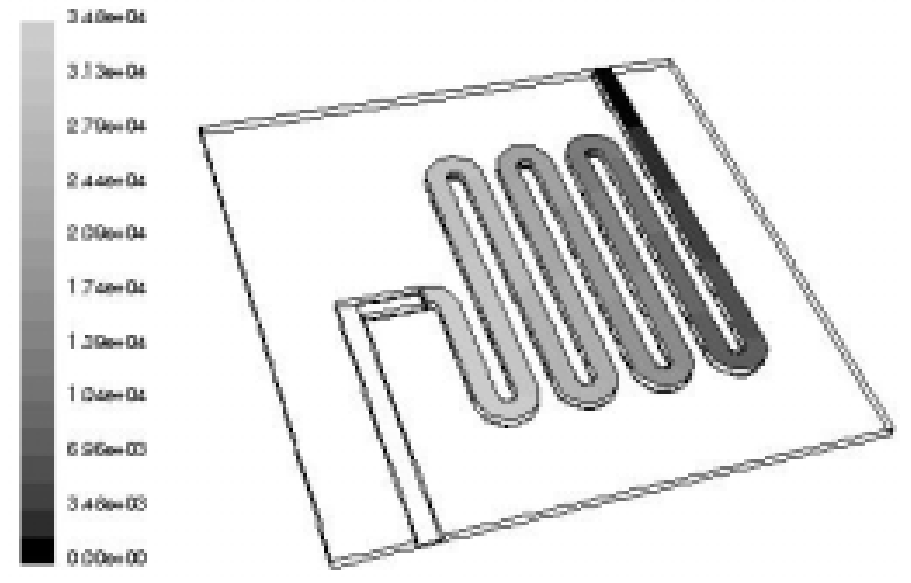

(b) pressure $(\mathrm{Pa})$

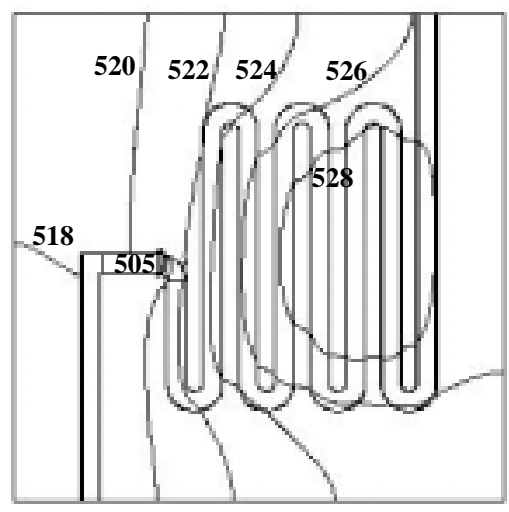

(c) temperature $(\mathrm{K})$
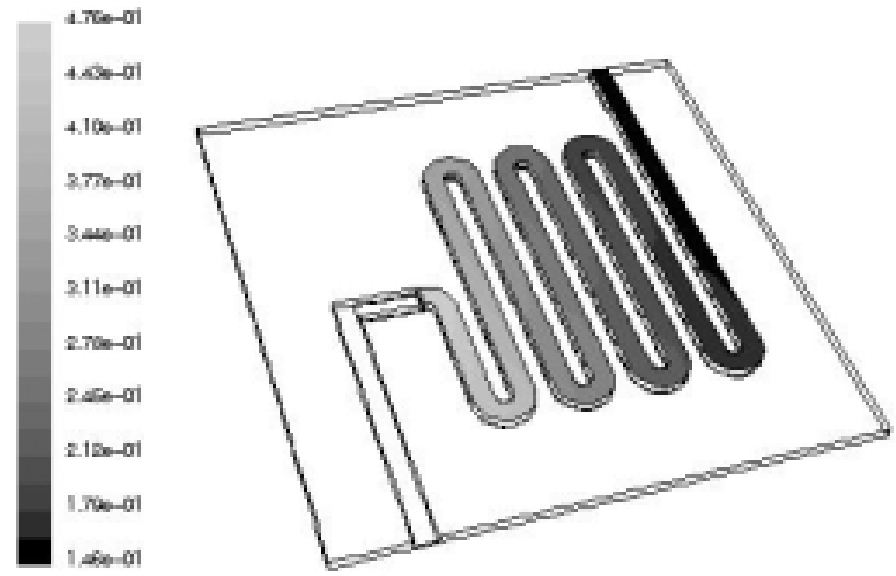

(d) $x_{\mathrm{CH} 3 \mathrm{OH}}$ 


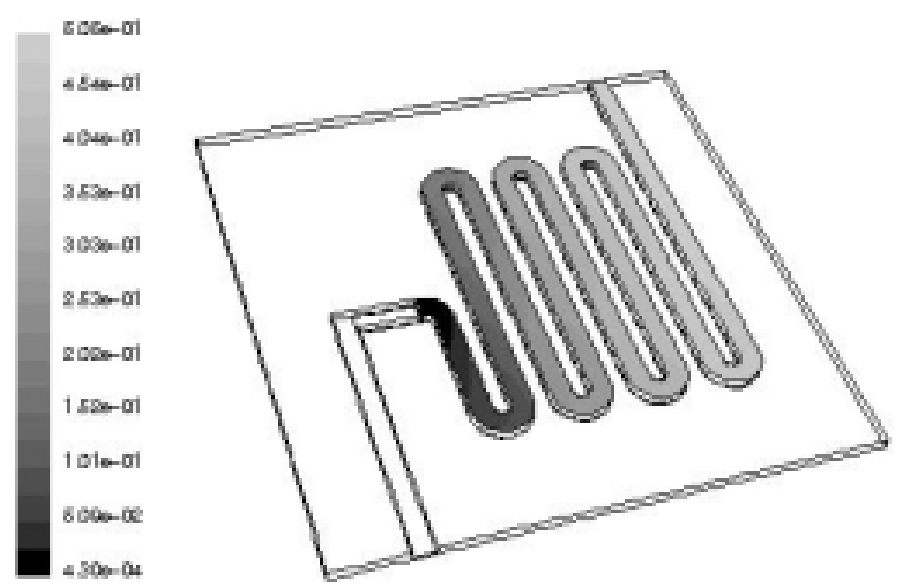

(e) $\boldsymbol{x}_{\mathrm{H} 2}$

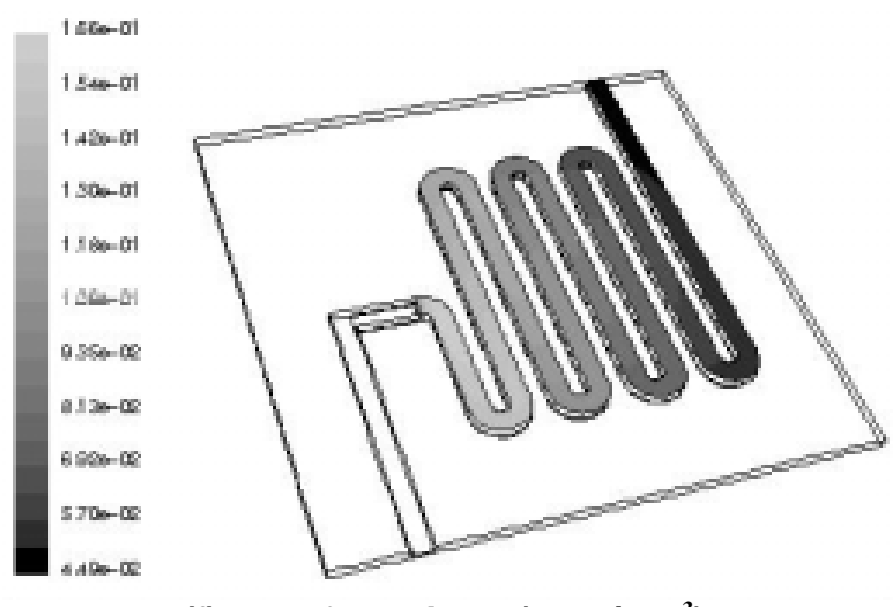

(f) rate of reaction $1\left(\mathrm{kmol} / \mathrm{s} \cdot \mathrm{m}^{3}\right)$

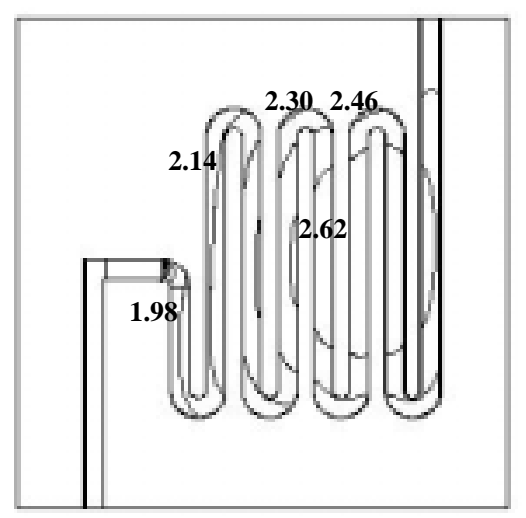

(g) rate of reaction $2\left(10^{-3} \mathrm{kmol} / \mathrm{s} \cdot \mathrm{m}^{3}\right)$

Fig. 8 Characteristics in a micro catalytic reformer

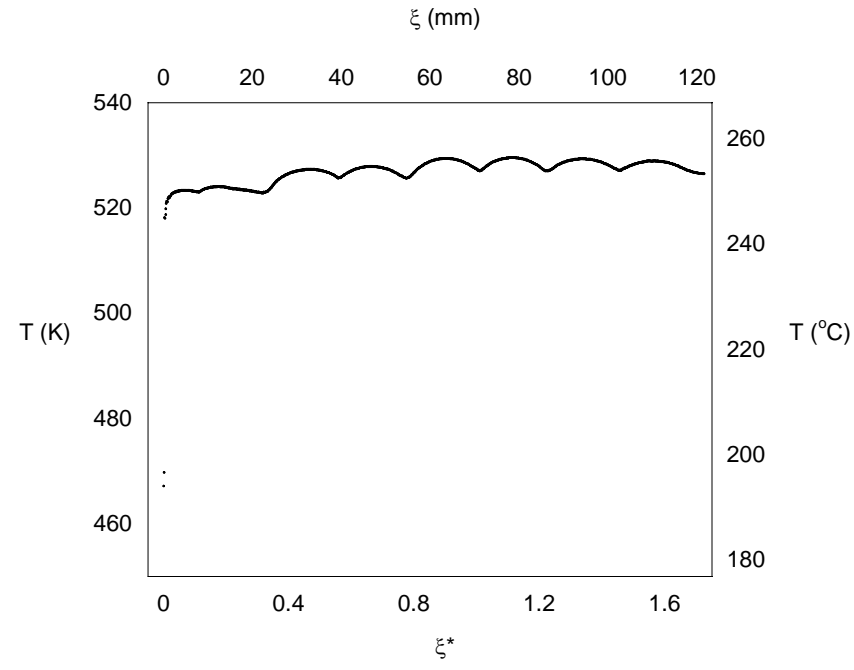

Fig. 9 Temperature variation along the reactor

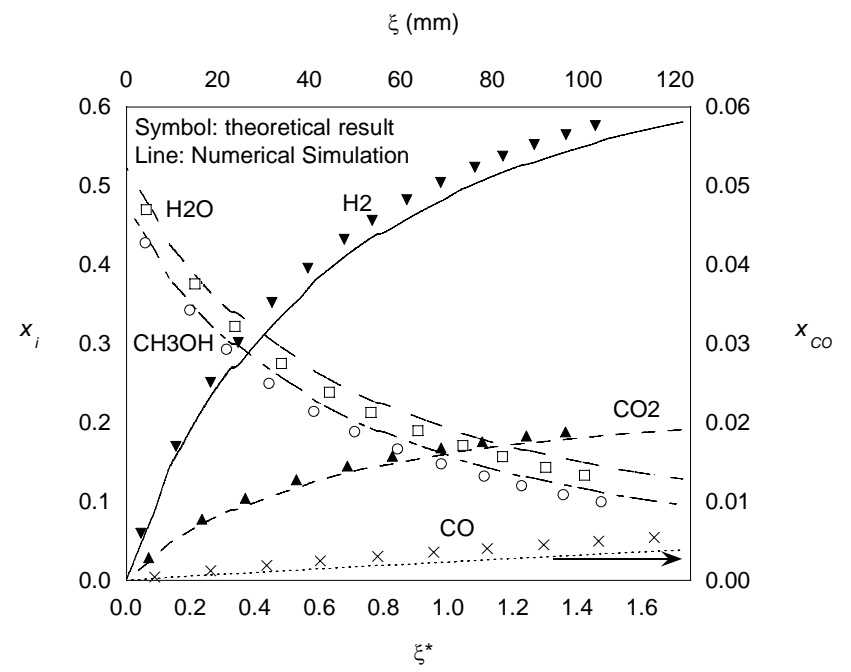

Fig. 10 Variation of mole fractions along the reactor

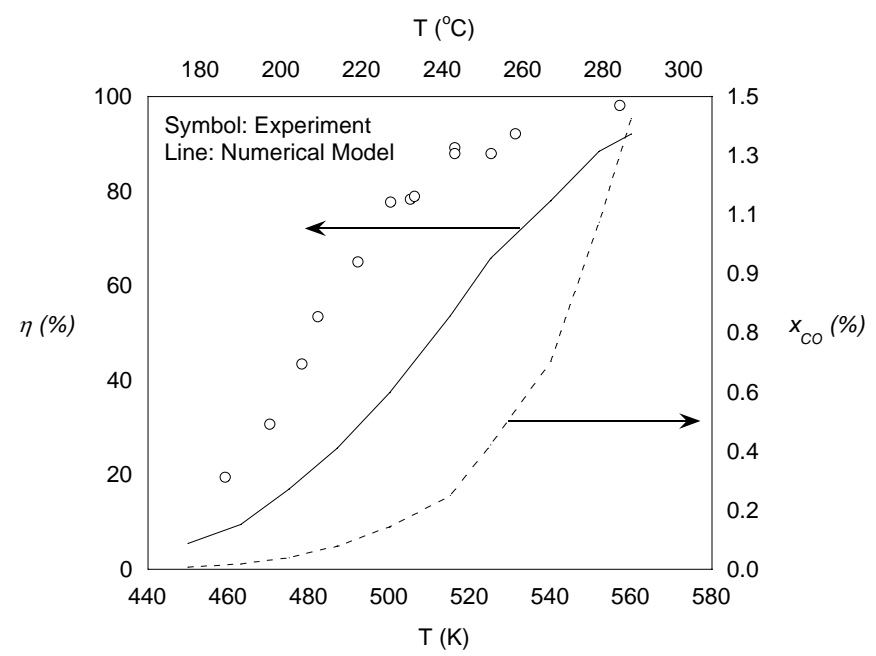

Fig. 11 Variations of conversion efficiency and the CO mole fraction with respect to temperature 